\title{
A Quantitative General Population Job Exposure Matrix for Occupational Noise Exposure
}

DOI:

10.1093/annweh/wxaa034

Document Version

Accepted author manuscript

Link to publication record in Manchester Research Explorer

\section{Citation for published version (APA):}

Stokholm, Z. A., Erlandsen, M., Schlünssen, V., Basinas, I., Bonde, J. P., Peters, S., Brandt, J., Vestergaard, J. M., \& Kolstad, H. A. (2020). A Quantitative General Population Job Exposure Matrix for Occupational Noise Exposure. Annals of Work Exposures and health. https://doi.org/10.1093/annweh/wxaa034

\section{Published in:}

Annals of Work Exposures and health

\section{Citing this paper}

Please note that where the full-text provided on Manchester Research Explorer is the Author Accepted Manuscript or Proof version this may differ from the final Published version. If citing, it is advised that you check and use the publisher's definitive version.

\section{General rights}

Copyright and moral rights for the publications made accessible in the Research Explorer are retained by the authors and/or other copyright owners and it is a condition of accessing publications that users recognise and abide by the legal requirements associated with these rights.

\section{Takedown policy}

If you believe that this document breaches copyright please refer to the University of Manchester's Takedown Procedures [http://man.ac.uk/04Y6Bo] or contact uml.scholarlycommunications@manchester.ac.uk providing relevant details, so we can investigate your claim.

\section{OPEN ACCESS}




\section{A quantitative general population job exposure matrix for occupational noise exposure}

Zara Ann Stokholm¹, Mogens Erlandsen², Vivi Schlünssen ${ }^{3,8}$, Ioannis Basinas ${ }^{4}$, Jens Peter Bonde ${ }^{5}$, Susan Peters ${ }^{6}$, Jens Brandt ${ }^{7}$, Jesper Medom Vestergaard ${ }^{1}$, Henrik Albert Kolstad ${ }^{1 *}$

${ }^{1}$ Department of Occupational Medicine, Danish Ramazzini Centre, Aarhus University Hospital, 8200 Aarhus N, Denmark; 2Section for Biostatistics, Department of Public Health, Aarhus University, 8000 Aarhus C, Denmark; ${ }^{3}$ Environment, Occupation and Health, Danish Ramazzini Centre, Department of Public Health, Aarhus University, 8000 Aarhus C, Denmark; ${ }^{4}$ Institute of Occupational Medicine, Edinburgh EH14 4AP, United Kingdom; ${ }^{5}$ Department of Occupational and Environmental Medicine, Bispebjerg University Hospital, 2400 Copenhagen, Denmark; ${ }^{6}$ Institute for Risk Assessment Sciences, Utrecht University, 3508 TD Utrecht, the Netherlands; ${ }^{7}$ CRECEA, 8000 Aarhus C, Denmark; ${ }^{8}$ National Research Centre for the Working Environment, 2100 Copenhagen, Denmark

Word count, main text: 3299, abstract: 275, 7 tables, 28 references

*Author to whom correspondence should be addressed. Tel: +45 7845 0900; Email: henkol@rm.dk

\section{Abstract}

Occupational noise exposure is a known risk factor for hearing loss and also adverse cardiovascular effects have been suggested. A job exposure matrix (JEM) would enable studies of noise and health on a large scale. The objective of this study was to create a quantitative JEM for occupational noise exposure assessment of the general working population.

Between 2001-03 and 2009-10, we recruited workers from companies within the 10 industries with the highest reporting of noise-induced hearing loss according to the Danish Working Environment Authority. We obtained 1343 personal occupational noise dosimeter measurements among 1140 workers representing 100 different jobs according to the Danish version of the International Standard Classification of Occupations 1988 (DISCO 88). Four experts used 35 of these jobs as benchmarks and rated noise levels for the remaining 337 jobs within DISCO 88. To estimate noise levels for all 372 jobs, we included expert ratings together with sex, age, occupational class and calendar year as fixed effects, 
while job and worker were included as random effects in a linear mixed regression model. The fixed effects explained $40 \%$ of the total variance: $72 \%$ of the between-jobs variance, $-6 \%$ of the between-workers variance and $4 \%$ of the within-worker variance. Modelled noise levels showed a monotonic increase with increasing expert score and a $20 \mathrm{~dB}$ difference between the highest and lowest exposed jobs. Based on the JEM estimates, metal wheel-grinders were among the highest and finance and sales professionals among the lowest exposed. This JEM of occupational noise exposure can be used to prioritise preventive efforts of occupational noise exposure and to provide quantitative estimates of contemporary exposure levels in epidemiological studies of health effects potentially associated with noise exposure.

\section{Search terms}

Job exposure matrix for occupational noise exposure, Occupational noise exposure, JEM, Epidemiological studies, Job

\section{Bottom 5 keywords}

Noise exposure*, job exposure matrix (JEM)*, occupational*, epidemiology*, mixed effects model* 


\section{Introduction}

Occupational noise is a known risk factor for hearing loss (Prince, 2002) and other health effects (Selander et al., 2016; Skogstad et al., 2016).

In Europe, $30 \%$ of the work force reported that they were exposed to noise so loud that they had to raise their voice and this proportion was unchanged from 2000-10 (Eurofound, 2016). However, in Europe no longitudinal surveillance data are available for occupational noise levels. In order to prioritise preventive efforts of health consequences of occupational noise exposure, there is a need for population-based overviews of the distribution of the relevant exposures across occupations. Such an overview can be provided by a quantitative general population job exposure matrix (JEM).

A JEM also enables estimation of job and calendar year specific exposure levels of occupational noise in community-based epidemiological studies investigating exposureresponse relations. Recently, general population JEMs have been developed using quantitative exposure information from a limited number of occupations in combination with expert rating (Friesen et al., 2012; Peters et al., 2011; Vested et al., 2019; Wild et al., 2002). This approach allows calibration of the experts' ratings as well as assignment of exposure level to occupations without measurements.

We describe a quantitative JEM for occupational noise exposure assessment of the general working population combining personal noise exposure measurements with expert ratings.

\section{Methods}

\section{Data collection and selection}

\section{Companies}

During 2001-03 and 2009-10, we recruited workers in companies from the 10 industries reported having the highest frequency of noise-induced hearing loss in Denmark according to the Danish Working Environment Authority: manufacturers of food, wood products, nonmetallic mineral products, basic metals, fabricated metal, machinery, motor vehicles, furniture, publishing and printing, and construction (The Danish Working Environment Authority, 2019). For optimizing the range in exposure levels and the between group variability, we also recruited workers of financial services. Finally, children's day care facilities were included as recent measurements in Denmark had indicated that workers of 
these units were exposed to high noise levels. Overall, 175 companies were enrolled in the two measurement campaigns, both performed as part of epidemiological studies previously described (Kock et al., 2004; Rubak et al., 2008; Stokholm et al., 2014).

Briefly, Statistics Denmark, a governmental organisation (Thygesen et al., 2011) in 2001 provided a list of 840 eligible companies in 2001 , with $\geq 15$ workers within the selected industries. During 2001 -2003, we randomly enlisted five companies with 15-49 workers and five companies with $\geq 50$ workers from each industry. From each company a maximum of 10 workers were selected by foremen and managers. In 2009-10 we asked these companies to participate again in a new measurement campaign and in case they declined or were closed, we invited other companies within the same industries in order to approach the initial number of companies.

\section{Workers}

Furthermore, we re-invited identifiable 2001-03 participants in the subsequent 2009-10 campaign. In total, the study population then included 1140 workers, 203 participated twice contributing $30 \%$ of all noise measurements (Table 1).

All workers filled in a questionnaire providing information on job according to DISCO 88, the Danish version of the International Classification of Occupations (ISCO 88) containing 372 occupations on a 4-digit level (DISCO, 2011), and use of hearing protection devices. During measurement days, the workers also provided information on work schedules. Furthermore, a subgroup of 334 workers filled in a log-book with detailed information on usage of hearing protection devices during the shift. Age and sex were extracted from the civil registration number (Pedersen, 2011).

The study protocol was approved by the local ethics committee (M-20080239) and the Danish Data Protection Agency (2009-41-3072) and participants gave written, informed consent.

\section{Noise exposure measurements}

Noise measurements started throughout the day, and not necessarily when work started, and ended about 24 hours later. Only measurements during work were included and not necessarily the complete working time. Sampling time was defined by the research team. We measured noise level as A-weighted equivalent sound level means ( $\mathrm{LEQ}_{\mathrm{EQ}}$ ) by personal dosimeters (Brüel \& Kjær, model 4443 and 4445) recording every 5 seconds for 24 hours 
including one work shift. In the first measurement campaign in 2001-2003, dosimeters were set to a 50-120 dBA range. In the second campaign, dosimeters were set to a 70-140 dBA range. Therefore, all measurements were standardized to a common 70-120 dBA range. For any noise recording falling below the limit of detection, a value of $50 \mathrm{dBA}$ replaced the nondetected level (the $\mathrm{LOD} / \sqrt{ } 2$ for each non-detectable value, where LOD is the limit of detection) (Burns et al., 2016; Hornung and Reed, 1990). All measurements were synchronized with questionnaire information, so each 5 second measurement relative to work, off-work or night time could be identified. All individual noise recordings during work were transformed from $\mathrm{dBA}$ to intensity, and an arithmetic mean was computed before transforming back to dBA yielding personal occupational noise intensity levels, hereafter referred to as noise levels according to the following formula: $10 \mathrm{x} \log \left[\sum\left(10^{\mathrm{dB}(\mathrm{A}) / 10} \mathrm{x} \mathrm{T}\right)\right]$. Measurements were obtained on ordinary working days all year round to account for potential seasonal variation in exposure.

\section{Expert assessment}

During 2016, four specialists in occupational medicine with at least 10 years of experience evaluating occupational exposures within industries and jobs rated noise levels for jobs included in DISCO 88. In order to qualify ratings, we a priori randomly selected approximately half $(\mathrm{n}=35)$ of the jobs with $\geq 5$ noise measurements (mean of 21 measurements per job) in our database to benchmark their assessments. For these jobs, the experts were informed on mean, median and range of $\mathrm{dBA}$ values measured, and the number of underlying measurements. The experts independently rated the expected average exposure intensity for a worker during a standard working day of 7.5 hour for each of the remaining 337 jobs (22 jobs with estimated noise exposure level blinded to the experts and 315 jobs with no or $<5$ measurements $(n=43)$ and classified each job as low level $(<80 \mathrm{dBA})$, medium level (80-84 dBA) or high level ( $\geq 85 \mathrm{dBA}$ ) exposed. The experts discussed discrepancies in ratings; based on relevant literature and sound arguments they reached consensus for all jobs. Before discussing discrepancies and reaching final consensus, 3 or all 4 experts agreed on the ratings in $85 \%$ of the cases, with a kappa of 0.77 for the overall agreements between the experts.

\section{Statistical methods}

Noise exposure grouping strategy 
In order to examine variance components and predictors of noise exposure intensity, we fitted linear mixed effect models in STATA (mixed-command) using restricted maximum likelihood estimation, with mean noise exposure level as the dependent variable and job and worker as random effects including all measurements. We checked the adequacy of the models confirming the normal distribution of the residuals by QQ-plots and linearity/homogeneity by scatterplots of the residuals versus fitted values.

\section{Statistical model}

The model structure was:

$\mathrm{Y}=\beta_{0}+\beta_{\text {sex }}+\beta_{\text {age }}+\beta\left(I_{\text {benchmark }} \times I_{\text {rating }}\right)+\beta_{\text {occupational class }}+\beta\left(\right.$ Calendar year $\times$ I $\left.\beta_{\text {occupational class }}\right)$ $+b_{\text {job }}+b_{\text {worker }}+\varepsilon$

The model terms were:

$\mathrm{Y}$ : noise level in $\mathrm{dB}$

$\beta_{0}$ : model intercept

$\beta_{\text {sex }}$ : categorical variable for sex (woman used as reference)

$\beta_{\text {age: }}$ continuous variable for age (40-year-old as reference)

$\beta$ ( $I_{\text {benchmark }} \mathrm{X} I_{\text {rating }}$ ): categorical interaction term between benchmark (yes, no) and expert rating (low, medium, high exposed)

$\beta_{\text {occupational class: categorical variable for occupational class (blue-, white-collar used as }}$ reference)

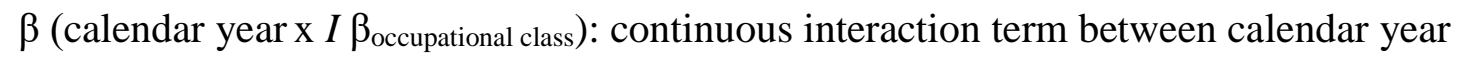
(continuous with 2010 as a reference) and occupational class (blue-, white-collar) $b_{\text {job}}$ : random effect term for job

$b_{\text {worker: }}$ random effect term for worker

$\varepsilon$ : residual error (within worker)

Information on sampling duration was also assessed but not included in the model because of statistical insignificance ( $\mathrm{p}$-value $>0.05$ ). P-values were not corrected for model selection or multiple testing.

The random effect terms $b_{\text {job }}$ and $b_{\text {worker were assumed statistically independent and normally }}$ distributed with means 0 and two different variance components representing the between job variance and the between worker (within job) variance. We obtained best linear unbiased predictions (BLUPs) of the coefficients for each of the jobs with noise measurements $(n=100)$. The BLUPs shrink the estimates toward the overall mean exposure of the expert 
score when there are few measurements and pulls the estimates toward the individual measurements when either there are more measurements available or the exposure variability is low.

We aimed at assessing noise exposure levels for each of the 372 jobs described by the DISCO 88. Jobs without measurements were assigned the weighted mean noise exposure level derived from the model for the corresponding category of the expert ratings. For jobs with exposure measurements available, the job specific prediction from the statistical model (BLUP) was added to the noise exposure estimate. Thus, an exposure level for all 372 jobs, sex, age, benchmark and year were estimated.

All analyses were performed using STATA 14.1 (StataCorp LP, College Station, TX, USA).

\section{Results}

Noise levels varied between 56 and $107 \mathrm{dBA}$ with an arithmetic mean of $81.7 \mathrm{dBA}$ and a SD of 6.6. Noise level increased through the expert ratings and was higher among blue-collar jobs. Mean noise exposure decreased with increasing calendar year and age and was lower among women than men (Table 2).

Table 3 presents variance components for noise level from the mixed effects model. More than $50 \%(25.4 / 46.6)$ of the total variance was between jobs as can be seen from the null model that only included random effects. By including sex and age as fixed effects, we observed a $6 \%$ reduction of the variance between jobs. When we added the interaction term between benchmark and expert rating as fixed effect this value increased to $69 \%$, reaching finally a $71 \%$ reduction when we added occupational class and the interaction term between occupational class and calendar year as fixed effects in the final model.

The fixed effects model parameters are presented in Table 4. Noise level was higher among men and blue-collar workers. Noise level decreased with increasing age and showed an 0.1 dBA annual decline by increasing calendar year among blue-collar workers while no such trend was apparent for white-collar workers (test for interaction between occupational class and calendar year, $\mathrm{p}=0.012$ ). While medium exposed benchmark jobs were $1 \mathrm{dBA}$ higher than the medium exposed expert rated jobs ( 5.99 vs. $4.88 \mathrm{dBA}$ ), the corresponding difference was $3 \mathrm{dBA}$ for the high exposed jobs (9.48 vs. $6.41 \mathrm{dBA}$ ) (test for interaction between benchmark and expert rated jobs, $\mathrm{p}=0.025)$. 
Table 5 shows model-based mean noise levels (dBA) for the ten highest and the ten lowest exposed jobs as estimated for 40-year old male workers in 2010. Metal wheel-grinders, polishers and tool sharpeners presented the highest level of $88.9 \mathrm{dBA}$ while finance and sales associate professionals showed the lowest noise level of $70.2 \mathrm{dBA}$.

Among low, medium and high exposed workers, 12\%, 24\%, and 29\% used hearing protection according to log-book information (data not shown).

Supplementary table A presents the number of all 372 jobs as defined at the 4-digit level in DISCO 88 and the number of jobs represented in the dataset for the nine major job categories.

In total, $27 \%$ of all jobs were represented in our sample. We prioritized sampling of jobs with expected high noise exposure levels. A total of $46 \%$ of all jobs in the major job category 8 "Plant and machine operators and assemblers" were represented in the data. We also included low and medium exposed jobs. The noise JEM will be made freely available at the DOC-X homepage (http://doc-x.dk/).

\section{Discussion}

We created a general population quantitative JEM with estimates of personal occupational noise intensity level specific for sex, age and calendar year. The model calibrated the expert ratings to a scale (dBA). This enables assessment of job and calendar year specific exposure levels of occupational noise for all jobs represented in Denmark including those with missing quantitative information. The JEM will be applicable to epidemiological studies addressing exposure-response relations between occupational noise exposure and cardiovascular and other health effects hypothesized to be associated with noise exposure in and outside work.

Two JEMs of occupational noise exposure for the general population have previously been described. Sjöström et al. developed a Swedish expert based semi-quantitative 3-level JEM for 321 jobs within the Nordic Occupational Classification system based on ISCO 58. The expert assessment was informed on 569 measurements from 129 jobs. Twenty five percent of the measurements were personal and included both short-time and full-shift measurements from 1970-2004, with most measurements collected during 1995-1999 (Sjöström et al., 2013). Recently, Roberts et al. reported a quantitative JEM including 753,702 measurements among 443 broad level standard occupational classification groups in the US (Roberts et al., 2018). The measurements were mainly obtained from the US government occupational exposure 
databases (85\%), private industry (14\%), and published literature (1\%) and made according to the Occupational Safety and Health Administration's (OSHA) permissible exposure limit of $90 \mathrm{dBA}$ criterion level and threshold, and $5 \mathrm{a} \mathrm{dB}$ time-intensity exchange rate. They used imputation statistics for jobs with no available measurements(Roberts et al., 2018) and had previously conducted a meta-analysis to ensure high heterogeneity across different job titles (Cheng et al., 2018) . In contrast to this extensive dataset and to the Swedish JEM, we used personal noise measurements collected in accordance with a research protocol, thereby circumventing some problems with hot spot measurements or worst case sampling (Cherrie, 2003).

We observed that women were exposed to less noise than men within the same jobs and we were thus able to capture some of the exposure variation within jobs. Lacking ability to go beyond the job is a major limitation of most JEMs (Greenland et al., 2016; Kauppinen et al., 1992). There have previously been indications of sex differences in occupational exposure levels within the same jobs for assembly workers and janitors (Locke et al., 2014). Some argue that these differences could either be due to differences in either tasks or reporting (Eng et al., 2011; Lacourt et al., 2018), however, this might not always be the case (HeilskovHansen et al., 2014). It could be argued that the noise level difference observed is due to sex differences between jobs rather than within jobs, however in $52 \%$ of all jobs both men and women are represented. And for up to $62 \%$ of blue-collar jobs, measurements on both sexes were available (data not shown).

Interestingly, we also found a decrease of noise exposure by increasing age, which could reflect changes to less exposed tasks over working years within the same job (Cassidy, 2017).

To our knowledge, only few previous JEMs have combined expert ratings with measurements in a statistical model framework (Friesen et al., 2012; Peters et al., 2011; Vested et al., 2019). Applied in epidemiological studies, the use of general population JEMs have recently depicted the shape of the exposure response relation between low level asbestos and silica exposure and lung cancer in a population-based case control study (De Matteis et al., 2012; Olsson et al., 2017).

More than $50 \%$ of the total variance of our dataset was between jobs and this is more than often seen in general population or industry specific exposure (Friesen et al., 2012; Kromhout et al., 1993; Peters et al., 2011). Since noise exposure is prevalent in many jobs, this is expected to reflect considerable variation in noise levels across jobs (Kock et al., 2004). 
Measurements were performed in companies within industries with high reporting of noise induced hearing loss, which might overestimate noise exposure for the same jobs also represented in industries with lower noise levels and reporting of noise induced hearing loss.

Adding the fixed effects to the model explained up to $72 \%$ of the between job variance, mostly attributed to the expert ratings. This proportion was about $43 \%$ and $18 \%$ in Friesen's and Peters's studies of benzene and quartz exposure, respectively (Friesen et al., 2012; Peters et al., 2011). Hence, most of the variance could be attributed to jobs.

There is a general concern about lack in consistency for expert rating of occupational exposures, and the agreement between experts can vary from poor to very good depending on the exposure (Friesen et al., 2011; Teschke et al., 2002). In order to improve homogeneity between the different experts' ratings, we selected 35 benchmark jobs that permitted the experts to calibrate their estimates to a common scale. This resulted in a very good agreement between the experts (kappa $=0.77$ ) before discussing discrepancies and reaching final consensus (Teschke et al., 2002). Noise exposure increased monotonically with increasing expert rating, however, we observed that experts were not able to capture the full exposure contrast in noise exposure level by overestimating low and underestimating high noise levels.

A comprehensive study estimated historical levels and long-term trends in occupational exposures, and found that most exposures declined between $4 \%$ and $14 \%$ per year, with a median value of $8 \%$ per year influenced by exposure factors including type of monitoring, historical changes in the threshold limit values (TLVs), and period of sampling (Symanski et al., 1998). Several other papers have documented the same decreasing trend in occupational noise exposure (Joy and Middendorf, 2007; Middendorf, 2004; Neitzel et al., 2014; Neitzel et al., 2011; Sayler et al., 2019). Roberts et al., also reported decreasing occupational noise exposures in $40.9 \%$ of the major classification groups (Roberts et al., 2018). Parallel results have also been seen by others. Likewise, we observed a linear $0.1 \mathrm{~dB}$ annual decline of noise level among blue-collar workers. This finding provides the possibility to evaluate exposure changes over time that could be an important source of exposure misclassification if left unaccounted. Our dataset only included noise recordings made between 2001 and 2010. Extrapolating noise levels several years back in time based on the linear trend observed within this rather brief period is however not warranted. 
Our elaborated final model provides estimates of personal ambient noise exposure levels that may be significantly attenuated by hearing protection (Arlien-Søborg et al., 2016; Frederiksen et al., 2017; Stokholm et al., 2014). Based on questionnaire information, about $74 \%$ of highly exposed workers used hearing protective devices in our cohort. Neitzel et al. reported that workers exposed above $85 \mathrm{dBA}$ who reported always using hearing protective devices, actually only wore them one third of the time (Neitzel, Richard and Seixas, 2005), which was also the case in our population according to the log-book reporting. With information on the usage of hearing protection across jobs, it is possible to adjust exposure assessment. Mean noise level declined about $2 \mathrm{dBA}$ when accounting for the use of hearing protection devices in a subsample of this population assuming a reduction of an average $10 \mathrm{dBA}$ when wearing protection (Stokholm et al., 2014).

This study was performed in random samples of small and large companies within a range of selected industries with high reporting of noise induced hearing loss. Some of the reasons for declining participation (such as time lag or organizational changes) may not be related to noise levels, but there is a risk of bias if companies with high noise levels due to limited resources declined to participate, resulting in underestimation of actual noise levels. Still, it is plausible that companies that successfully have solved a noise problem would be less interested in participating. However, neither the participation rate at the industry nor the number of workers per industry was related to the measured noise levels. Workers were mainly selected by foremen and managers so as to have at least one employee from each work area, and this selection might have resulted in bias in an unpredictable direction. Nevertheless, we expect the measurements to be representative of these industries.

We did not have full-shift measurements for all workers, but sampling time was not defined by the participants but by the research team, and we regard the included measurements to be representative of full-shift levels. For that reason, it was not relevant to normalize levels to full shift duration.

We only had repeated measurements from a few workers. This could bias the results if only highly motivated workers chose to participate in both measurement campaigns. Still, about $50 \%$ of workers agreed to participate in the second campaign when re-invited. However, only $36 \%$ (18\% of all participants) had operational measurements, as the remaining were either performed during days off, or from unemployed or pensioned workers (Frederiksen et al., 2017). 
Some non-differential misclassification could also affect the results as 1-minute resolution questionnaire information was synchronized with 5-second resolution noise level data.

It is problematic to compare these model-based noise levels with the two previous published JEMs on noise exposure. In Europe, we use a stricter noise exposure standard than in the US ( $85 \mathrm{dBA}$ level and a $3 \mathrm{~dB}$ time-intensity exchange rate). Thus, US levels are expected to be higher(Roberts et al., 2018) . Furthermore, Roberts et al. used 443 jobs according to the broad standard occupational classification (SOC) and Sjöström et al. used 321 jobs classified according to the Nordic Occupational Classification system (NYK) (Sjöström et al., 2013), which likewise makes comparability difficult. However, it is possible to compare few jobs across the three JEMs. In the Swedish JEM most measurements were collected during 199599, and based on this assumption butchers, for example, are exposed to a median of $90 \mathrm{dBA}, \mathrm{a}$ mean of $90.6 \mathrm{dBA}$ according to Roberts et al. and a mean of $90.3 \mathrm{dBA}$ for a 40 -year old male in 1995 according to this JEM. The latter estimate reflected a $2.2 \mathrm{dBA}$ increase from 2010 back to 1995. An increase of $3 \mathrm{~dB}$ was observed for the major SOC group in the same period in the American JEM. Likewise, workshop mechanics are exposed to a mean of $82.7 \mathrm{~dB}$ in 2010 (reference year), corresponding to $85.0 \mathrm{dBA}$ in 1995 according to this JEM, a median of $88 \mathrm{dBA}$ in the Swedish JEM and $83.7 \mathrm{dBA}$ according to the American JEM.

\section{Conclusion}

The noise estimates of this JEM can guide future preventive efforts, not only focusing on specific jobs but also targeting age and sex. Additionally, this occupational noise exposure matrix can be used in epidemiological studies to investigate exposure-response relations between occupational noise exposure and health effects. This quantitative JEM is designed for epidemiological studies of the general population as noise exposure is ubiquitous and not restricted to specific industries. The JEM provides exposure levels by calendar year which is highly relevant for estimating duration of and cumulative contemporary noise exposure retrospectively, which may predict otological, cardiovascular and other non-contagious diseases. Furthermore, we showed the usefulness of applying benchmarks for the calibration of expert assessment. 


\section{References}

Arlien-Søborg MC, Schmedes AS, Stokholm ZA, Grynderup MB, Bonde JP, Jensen CS, Hansen ÅM, Frederiksen TW, Kristiansen J, Christensen KL, Vestergaard JM, Lund SP, Kolstad HA. (2016) Ambient and at-the-ear occupational noise exposure and serum lipid levels. Int Arch Occup Environ Health 89:1087-1093.

Burns KN, Sun K, Fobil JN, Neitzel RL. (2016) Heart rate, stress, and occupational noise exposure among electronic waste recycling workers. International Journal of Environmental Research and Public Health 13:140.

Cassidy H. (2017) Task variation within occupations. Ind Relat 56:393 410-410.

Cheng W, Roberts B, Mukherjee B, Neitzel RL. (2018) Meta-analysis of job-exposure matrix data from multiple sources. Journal of Exposure Science \& Environmental Epidemiology 28:259-274.

Cherrie JW. (2003) The beginning of the science underpinning occupational hygiene. Ann Occup Hyg 47:179.

De Matteis S, Consonni D, Lubin JH, Tucker M, Peters S, Vermeulen RC, Kromhout H, Bertazzi PA, Caporaso NE, Pesatori AC, Wacholder S, Landi MT. (2012) Impact of occupational carcinogens on lung cancer risk in a general population. Int J Epidemiol 41:711721.

DISCO. (2011) https://www.dst.dk/en/statistik/dokumentation/nomenklaturer/disco-88 (accessed 14 May 2019).

Eng A, 't Mannetje A, McLean D, Ellison-Loschmann L, Cheng S, Pearce N. (2011) Gender differences in occupational exposure patterns. Occup Environ Med 68:888-894.

Eurofound. (2016) Sixth European working conditions survey - overview report, publications office of the European union, Luxembourg.

http://www.eurofound.europa.eu/sites/default/files/ef_publication/field_ef_document/ef1634e n.pdf (accessed 14 May 2019).

Frederiksen TW, Ramlau-Hansen CH, Stokholm ZA, Grynderup MB, Hansen ÅM, Kristiansen J, Vestergaard JM, Bonde JP, Kolstad HA. (2017) Noise-induced hearing loss - A preventable disease? Results of a 10-year longitudinal study of workers exposed to occupational noise. Noise \& Health 19:103-111.

Friesen MC, Coble JB, Lu W, Shu XO, Ji BT, Xue S, Portengen L, Chow WH, Gao YT, Yang G, Rothman N, Vermeulen R. (2012) Combining a job-exposure matrix with exposure measurements to assess occupational exposure to benzene in a population cohort in shanghai, china. Ann Occup Hyg 56:80-91. 
Friesen MC, Coble JB, Katki HA, Ji B, Xue S, Lu W, Stewart PA. (2011) Validity and reliability of exposure assessors' ratings of exposure intensity by type of occupational questionnaire and type of rater. Ann Occup Hyg 55:601-611.

Greenland S, Fischer HJ, Kheifets L. (2016) Methods to explore uncertainty and bias introduced by job exposure matrices. Risk Anal 36:74-82.

Heilskov-Hansen T, SWS, Thomsen J, Mikkelsen S, Hansson G. (2014) Sex differences in task distribution and task exposures among danish house painters: An observational study combining questionnaire data with biomechanical measurements. PLoS One 9.

Hornung RW and Reed LD. (1990) Estimation of average concentration in the presence of non-detectable values. App Occup Environ Hyg 5:46-51.

Joy GJ and Middendorf PJ. (2007) Noise exposure and hearing conservation in U.S. coal mines-A surveillance report. Journal of Occupational and Environmental Hygiene 4:26-35.

Kauppinen TP, Mutanen PO, Seitsamo JT. (1992) Magnitude of misclassification bias when using a job-exposure matrix. Scand $J$ Work Environ Health 18:105.

Kock S, Andersen T, Kolstad HA, Kofoed-Nielsen B, Wiesler F, Bonde JP. (2004) Surveillance of noise exposure in the danish workplace: A baseline survey. Occup Environ Med 61:838-843.

Kromhout H, Symanski E, Rappaport SM. (1993) A comprehensive evaluation of within- and between-worker components of occupational exposure to chemical agents. Ann Occup Hyg 37:253-270.

Lacourt A, Labreche F, Goldberg MS, Siemiatycki J, Lavoue J. (2018) Agreement in occupational exposures between men and women using retrospective assessments by expert coders. Ann Work Expo Health.

Locke SJ, Colt JS, Stewart PA, Armenti KR, Baris D, Blair A, Cerhan JR, Chow W, Cozen W, Davis F, De Roos AJ, Hartge P, Karagas MR, Johnson A, Purdue MP, Rothman N, Schwartz K, Schwenn M, Severson R, Silverman DT, Friesen MC. (2014) Identifying gender differences in reported occupational information from three US population-based case-control studies. Occup Environ Med 71:855-864.

Middendorf PJ. (2004) Surveillance of occupational noise exposures using OSHA's integrated management information system. American Journal of Industrial Medicine 46:492-504.

Neitzel RL, Galusha D, Dixon-Ernst C, Rabinowitz PM. (2014) Methods for evaluating temporal trends in noise exposure. International Journal of Audiology 53:S76-S83.

Neitzel RL, Stover B, Seixas NS. (2011) Longitudinal assessment of noise exposure in a cohort of construction workers. Annals of Occupational Hygiene 55:906-916. 
Neitzel R and Seixas N. (2005) The effectiveness of hearing protection among construction workers. Journal of Occupational and Environmental Hygiene 2:227-238.

Olsson AC, Vermeulen R, Schuz J, Kromhout H, Pesch B, Peters S, Behrens T, Portengen L, Mirabelli D, Gustavsson P, Kendzia B, Almansa J, Luzon V, Vlaanderen J, Stucker I, Guida F, Consonni D, Caporaso N, Landi MT, Field J, Bruske I, Wichmann HE, Siemiatycki J, Parent ME, Richiardi L, Merletti F, Jockel KH, Ahrens W, Pohlabeln H, Plato N, Tardon A, Zaridze D, McLaughlin J, Demers P, Szeszenia-Dabrowska N, Lissowska J, Rudnai P, Fabianova E, Stanescu Dumitru R, Bencko V, Foretova L, Janout V, Boffetta P, Bueno-deMesquita B, Forastiere F, Bruning T, Straif K. (2017) Exposure-response analyses of asbestos and lung cancer subtypes in a pooled analysis of case-control studies. Epidemiology 28:288299.

Pedersen CB. (2011) The Danish civil registration system. Scand J Public Health 39:22-25.

Peters S, Vermeulen R, Cassidy A, 't Mannetje A, van Tongeren M, Boffetta P, Straif K, Kromhout H. (2011) Comparison of exposure assessment methods for occupational carcinogens in a multi-centre lung cancer case-control study. Occupational and Environmental Medicine 68:148-153.

Peters S, Vermeulen R, Portengen L, Olsson A, Kendzia B, Vincent R, Savary B, Lavoué J, Cavallo D, Cattaneo A, Mirabelli D, Plato N, Fevotte J, Pesch B, Brüning T, Straif K, Kromhout H. (2011) Modelling of occupational respirable crystalline silica exposure for quantitative exposure assessment in community-based case-control studies. Journal of Environmental Monitoring: JEM 13:3262-3268.

Prince MM. (2002) Distribution of risk factors for hearing loss: Implications for evaluating risk of occupational noise-induced hearing loss. The Journal of the Acoustical Society of America 112:557-567.

Roberts B, Cheng W, Mukherjee B, Neitzel RL. (2018) Imputation of missing values in a large job exposure matrix using hierarchical information. J Expo Sci Environ Epidemiol.

Rubak T, Kock S, Koefoed-Nielsen B, Peter Lund S, Peter Bonde J, Kolstad HA. (2008) The risk of tinnitus following occupational noise exposure in workers with hearing loss or normal hearing. International Journal of Audiology 47:109-114.

Sayler SK, Roberts BJ, Manning MA, Sun K, Neitzel RL. (2019) Patterns and trends in OSHA occupational noise exposure measurements from 1979 to 2013. Occup Environ Med 76:118-124.

Selander J, Albin M, Rosenhall U, Rylander L, Lewne M, Gustavsson P. (2016) Maternal occupational exposure to noise during pregnancy and hearing dysfunction in children: A nationwide prospective cohort study in sweden. Environmental Health Perspectives 124:855860. 
Sjöström M, Lewné M, Alderling M, Willix P, Berg P, Gustavsson P, Svartengren M. (2013) A job-exposure matrix for occupational noise: Development and validation. Ann Occup Hyg 57:774.

Skogstad M, Johannessen HA, Tynes T, Mehlum IS, Nordby KC, Lie A. (2016) Systematic review of the cardiovascular effects of occupational noise. Occup Med (Lond ) 66:10-16.

Stokholm ZA, Hansen ÅM, Grynderup MB, Bonde JP, Christensen KL, Frederiksen TW, Lund SP, Vestergaard JM, Kolstad HA. (2014) Recent and long-term occupational noise exposure and salivary cortisol level. Psychoneuroendocrinology 39:21-32.

Symanski E, Kupper LL, Hertz-Picciotto I, Rappaport SM. (1998) Methodology:

Comprehensive evaluation of long term trends in occupational exposure: Part 2. predictive models for declining exposures. Occup Environ Med 55:310-316.

Teschke K, Olshan AF, Daniels JL, De Roos AJ, Parks CG, Schulz M, Vaughan TL. (2002) Occupational exposure assessment in case-control studies: Opportunities for improvement. Occup Environ Med 59:575-93; discussion 594.

The Danish Working Environment Authority. (2019) https://osha.europa.eu/en/about-euosha/national-focal-points/denmark. (accessed 14 May 2019).

Thygesen LC, Daasnes C, Thaulow I, BrÃ snnum-Hansen H. (2011) Introduction to Danish (nationwide) registers on health and social issues: Structure, access, legislation, and archiving. Scandinavian Journal of Public Health 39:12-16.

Vested A, Schlunssen V, Burdorf A, Andersen JH, Christoffersen J, Daugaard S, Flachs EM, Garde AH, Hansen AM, Markvart J, Peters S, Stokholm Z, Vestergaard JM, Vistisen HT, Kolstad HA. (2019) A quantitative general population job exposure matrix for occupational daytime light exposure. Ann Work Expo Health 63:666-678.

Wild P, Sauleau EA, Bourgkard E, Moulin JJ. (2002) Combining expert ratings and exposure measurements: A random effect paradigm. Ann Occup Hyg 46:479-487. 
Table 1. Number of companies, jobs, workers and noise measurements by calendar year

\begin{tabular}{|c|c|c|c|c|c|c|c|c|}
\hline & \multicolumn{2}{|c|}{ Companies } & \multicolumn{2}{|c|}{ Jobs $^{\mathrm{a}}$} & \multicolumn{2}{|c|}{ Workers } & \multicolumn{2}{|c|}{ Measurements } \\
\hline & $\mathrm{N}$ & $\%$ & $\mathrm{~N}$ & $\%$ & $\mathrm{~N}$ & $\%$ & $\mathrm{~N}$ & $\%$ \\
\hline $2001-03$ & 23 & 13 & 16 & 16 & 532 & 47 & 532 & 40 \\
\hline $2001-03 \& 2009-10$ & 62 & 35 & 62 & 62 & 203 & 18 & 406 & 30 \\
\hline $2009-10$ & 90 & 52 & 22 & 22 & 405 & 35 & 405 & 30 \\
\hline Total & 175 & 100 & 100 & 100 & 1140 & 100 & 1343 & 100 \\
\hline
\end{tabular}

aJobs within the DISCO 88, the Danish version of the International Standard Classification of Occupations (ISCO), revision 1988 
Table 2. Number of samples and distribution of noise levels (dBA), overall and by level of selected variables

\begin{tabular}{lllll}
\hline Variable & $\mathrm{N}^{\mathrm{a}}$ & $\%^{\mathrm{b}}$ & Mean & SD
\end{tabular}

Overall

Sex

Women

Men

Age (tertiles)

18-37 years

$38-46$ years

47-65 years

Rating

Low exposed

Medium exposed

High exposed

Calendar year

2001
2002
2003
2009
2010

Occupational class

White-collar

Blue-collar

1343

100

81.7

$\begin{array}{llll}323 & 24 & 78.3 & 7.1\end{array}$

$\begin{array}{llll}1020 & 76 & 82.8 & 6.0\end{array}$

$\begin{array}{llll}470 & 35 & 82.4 & 6.8\end{array}$

$\begin{array}{llll}457 & 34 & 81.6 & 6.3\end{array}$

$\begin{array}{llll}416 & 31 & 81.2 & 6.5\end{array}$

$\begin{array}{llll}250 & 19 & 74.2 & 7.3\end{array}$

$\begin{array}{llll}541 & 40 & 81.9 & 4.4\end{array}$

$\begin{array}{llll}552 & 41 & 85.0 & 5.0\end{array}$

$\begin{array}{rrrr}52 & 4 & 84.4 & 5.4 \\ 599 & 45 & 82.2 & 6.5 \\ 84 & 6 & 82.6 & 6.7 \\ 333 & 25 & 81.3 & 6.4 \\ 275 & 20 & 80.5 & 6.7\end{array}$

$\begin{array}{llll}275 & 20 & 80.5 & 6.7\end{array}$

$\begin{array}{rrrr}299 & 22 & 75.6 & 7.5 \\ 1044 & 78 & 83.5 & 5.0\end{array}$

${ }^{\mathrm{a}}$ Number of samples; ${ }^{b}$ Relative percentages of samples by level 
Table 3. Variance components for noise level (dBA) from the mixed effects model $(n=1343)$

\begin{tabular}{lrrrrrrr}
\hline Variance components & Null model $^{\mathrm{a}}$ & $\begin{array}{c}\text { Intermediate } \\
\text { model } 1^{\mathrm{b}}\end{array}$ & \multicolumn{2}{c}{$\begin{array}{c}\text { Intermediate } \\
\text { model } 2^{\mathrm{c}}\end{array}$} & \multicolumn{2}{c}{ Final model $^{\mathrm{d}}$} \\
& Variance (\%) & Variance & $\%^{\mathrm{f}}$ & Variance & $\%^{\mathrm{f}}$ & Variance & $\%^{\mathrm{f}}$ \\
\hline Between jobs & $25.4(54)$ & 24.0 & 6 & 7.9 & 69 & 7.1 & 72 \\
Between workers & $5.0(11)$ & 5.0 & 0 & 5.1 & -2 & 5.3 & -6 \\
Within worker & $16.2(35)$ & 15.9 & 2 & 15.9 & 2 & 15.5 & 4 \\
\hline Total & $46.6(100)$ & 44.9 & 4 & 28.9 & 38 & 27.9 & 40
\end{tabular}

${ }^{\mathrm{a}}$ Null model includes job and subject id as random effects; ${ }^{\mathrm{b}}$ Intermediate model 1 includes in addition to the previous random effects, sex and age as fixed effects; ${ }^{\mathrm{c}}$ Intermediate model 2 includes in addition to model 1 , the interaction term between benchmark and expert rating as fixed effects; ${ }^{\mathrm{d}}$ Final model includes in addition to model 2, occupational class and an interaction term between occupational class and calendar year as fixed effects; ${ }^{\mathrm{f}}$ Percentage reduction of variance explained by fixed effects when compared with null model 
Table 4. Fixed effects model parameters for noise levels $(\mathrm{dBA})(\mathrm{n}=1343)$

\begin{tabular}{llrrr}
\hline & $\beta$ & SE & $P$-value \\
\hline Intercept & & 72.88 & 1.22 & $<0.001$ \\
Sex & & & \\
& Woman & Ref. & & \\
& Man & 1.25 & 0.41 & 0.002
\end{tabular}

Occupational class

White-collar

Blue-collar

$\operatorname{Age}^{\mathrm{a}}$

Calendar year*occupational class ${ }^{\mathrm{b}}$

White-collar

Blue-collar

Benchmark $^{\mathrm{c} *}$ rating $^{\mathrm{d}}$

Yes

Low exposed

Medium exposed

High exposed

No

Low exposed

Medium exposed

High exposed

Ref.

$\begin{array}{lll}2.77 & 1.08 & 0.011\end{array}$

$\begin{array}{lll}-0.04 & 0.01 & 0.012\end{array}$

$\begin{array}{lll}0.06 & 0.07 & 0.357\end{array}$

$\begin{array}{lll}-0.14 & 0.04 & <0.001\end{array}$

0.025

Ref.

$\begin{array}{lll}5.99 & 1.48 & <0.001 \\ 9.48 & 1.71 & <0.001\end{array}$

$\begin{array}{lll}1.87 & 1.36 & 0.172\end{array}$

$\begin{array}{lll}4.87 & 1.74 & 0.006\end{array}$

$\begin{array}{lll}6.41 & 1.64 & <0.001\end{array}$

\footnotetext{
${ }^{\mathrm{a}} \mathrm{Age}$ is standardised to 40 years (continuous); ${ }^{\mathrm{b}}$ Interaction term between calendar year standardised to year 2010 (continuous) and occupational class (dichotomous); ${ }^{\circ}$ Expert rating for no benchmark group (low, medium, high exposed); ${ }^{b}$ Interaction term between benchmark and ratings
} 
Table 5. Model-based noise level (dBA) for the ten highest and the ten lowest exposed jobs as estimated for a 40-year old male worker in 2010 among 100 estimated jobs

\begin{tabular}{llll}
\hline Jobs $^{\text {a }}$ & Job description & N & Mean \\
\hline Ten highest exposed jobs & & \\
7224 & Metal wheel-grinders, polishers and tool sharpeners & 6 & 88.9 \\
8123 & Metal-heat-treating-plant operators & 8 & 88.7 \\
7411 & Butchers, fishmongers and related food preparers & 11 & 88.1 \\
8275 & Fruit-, vegetable- and nut-processing-machine operators & 6 & 86.8 \\
8240 & Wood-products machine operators & 37 & 86.3 \\
8271 & Meat- and fish-processing-machine operators & 20 & 85.9 \\
7212 & Welders and flame cutters & 6 & 85.8 \\
7423 & Woodworking machine setters and setter-operators & 35 & 85.7 \\
7211 & Metal molders and core makers & 12 & 85.6 \\
8274 & Baked-goods, cereal and chocolate-products machine operators & 8 & 85.5
\end{tabular}

Ten lowest exposed jobs

$3419 \quad$ Finance and sales associate professionals not elsewhere classified $\quad<4 \quad 70.2$

$4212 \quad$ Tellers and other counter clerks $\quad<4 \quad 70.3$

$2441 \quad$ Economists $\quad<4 \quad 70.7$

$2419 \quad$ Business professionals not elsewhere classified $\quad 17 \quad 71.8$

$\begin{array}{lll}4190 & \text { Other office clerks } & 1271.9\end{array}$

1227 Production and operations department managers in business services $\quad<4 \quad 72.0$

$3411 \quad$ Securities and finance dealers and brokers $\quad<4 \quad 72.8$

$\begin{array}{lll}3118 & \text { Draughts persons } & <43.0\end{array}$

$2351 \quad$ Education methods specialists $\quad<4 \quad 73.6$

$1231 \quad$ Finance and administration department managers $\quad<4 \quad 74.1$

aJobs within the DISCO 88, the Danish version of the International Standard Classification of Occupations (ISCO), revision 1988 


\section{Supplementary material}

Table A. Number of jobs defined at the 4-digit level within the nine major groups and the number of jobs with noise level measurements

\begin{tabular}{lrrr}
\hline Major groups $^{\text {a }}$ & Total & \multicolumn{2}{c}{$\begin{array}{c}\text { Jobs with } \\
\text { measurements }\end{array}$} \\
\cline { 2 - 5 } & $\mathrm{N}$ & $\mathrm{N}$ & $\%$ \\
\hline Overall & 372 & 100 & 27 \\
1 Legislators, senior officials and managers & 32 & 5 & 16 \\
2 Professionals & 55 & 6 & 11 \\
3 Technicians and associate professionals & 70 & 12 & 17 \\
4 Clerks & 22 & 7 & 32 \\
5 Service workers and shop and market sales workers & 20 & $<4$ & 15 \\
6 Skilled agricultural and fishery workers & 12 & $<4$ & 8 \\
7 Craft and related trades workers & 71 & 28 & 39 \\
8 Plant and machine operators and assemblers & 70 & 32 & 46 \\
9 Elementary occupations & 20 & 6 & 30 \\
\hline
\end{tabular}

${ }^{a}$ Major groups within the DISCO 88, the Danish version of the International Standard Classification of Occupations (ISCO), revision 1988 